\title{
APRESENTAÇÃO
}

Temos o direito a ser iguais sempre que a diferença nos inferioriza; temos o direito a ser diferentes sempre que a igualdade nos descaracteriza. (Boaventura de Souza Santos, 2006, p. 316)

\section{Desigualdades e diversidade na educação}

$\mathrm{N}$ os últimos anos, a relação entre desigualdades e diversidade tem ocupado um lugar de maior destaque no debate contemporâneo. No que se refere à diversidade, Abramowicz, Rodrigues e Cruz (2011) refletem que a sua discussão, com enfoque na heterogeneidade de culturas que marca a sociedade atual, é realizada em oposição ao modelo de Estado-nação moderno, liberal e ocidental e se faz presente em grande parte dos países do mundo.

As autoras alertam para o fato de que o debate sobre a diversidade se diferencia nacional e internacionalmente de acordo com o seu período de emergência, as causas principais que geram ou impõem a discussão sobre determinados grupos, identidades culturais, espaciais e territoriais, discriminação, entre outros. Imigração, gênero, sexualidade, raça, etnia, religião, língua, espaços/territórios são os principais fatores e temáticas que desencadearam um processo de mobilização e discussão sobre a diversidade, sendo que em vários contextos eles estão interrelacionados ou interseccionados.

A diversidade, entendida como construção histórica, social, cultural e política das diferenças, realiza-se em meio às relações de poder e ao crescimento das desigualdades e da crise econômica que se acentuam no contexto nacional e internacional. Não se pode negar, nesse debate, os efeitos da desigualdade socioeconômica sobre toda a sociedade e, em especial, sobre os coletivos sociais considerados diversos. Portanto, a análise sobre a trama desigualdades e diversidade deverá ser realizada levando em consideração a sua interrelação com alguns fatores, tais como: os desafios da articulação entre políticas de igualdade e políticas de identidade ou de reconhecimento da diferença no contexto nacional e internacional, a necessária reinvenção do Estado rumo à emancipação social, o acirramento da pobreza e a desigual distribuição de renda da população, os atuais avanços e desafios dos setores populares e dos movimentos sociais em relação ao acesso à educação, à moradia, ao trabalho, à saúde e aos bens culturais, bem como os impactos da relação entre igualdade, desigualdades e diversidade nas políticas públicas.

No Brasil, diferentes alternativas e proposições econômicas, políticas e teóricas têm sido desencadeadas na tentativa de apontar caminhos para essa situação. 
Desde o processo de reabertura política a partir dos anos de 1980 aos dias atuais, vem se configurando um novo foco de interpretações a respeito de como equacionar a oferta da educação pública no contexto das desigualdades socioeconômicas e da diversidade. A postura central dos movimentos sociais, dos profissionais da educação e daqueles comprometidos com uma sociedade democrática e com a educação pública, gratuita e laica tem sido reafirmar o princípio constitucional contido no artigo 205 da Constituição Federal de 1988, ou seja, “a educação, direito de todos e dever do Estado e da família, será promovida e incentivada com a colaboração da sociedade, visando ao pleno desenvolvimento da pessoa, seu preparo para o exercício da cidadania e sua qualificação para o trabalho".

Portanto, não se educa "para alguma coisa", educa-se porque a educação é um direito e, como tal, deve ser garantido de forma igualitária, equânime e justa. O objetivo da educação e das suas políticas não é formar gerações para o mercado, para o vestibular ou, tampouco, atingir os índices internacionais de alfabetização e matematização. $\mathrm{O}$ foco central são os sujeitos sociais, entendidos como cidadãos e sujeitos de direitos. Essa interpretação tem sido adensada do ponto de vista político e epistemológico pelos movimentos sociais ao enfatizarem que os sujeitos de direitos são também diversos em raça, etnia, credo, gênero, orientação sexual e idade, entre outros. Enfatizam, também, que essa diversidade tem sido tratada de forma desigual e discriminatória ao longo dos séculos e ainda não foi devidamente equacionada pelas políticas de Estado, pelas escolas e seus currículos.

Dessa forma, devido às pressões sociais, o entendimento da diversidade como construção social constituinte dos processos históricos, culturais, políticos, econômicos e educacionais e não mais vista como um "problema" começa a ter mais espaço na sociedade, nos fóruns políticos, nas teorias sociais e educacionais.

São também os movimentos sociais, principalmente os de caráter identitário (indígenas, negros, quilombolas, feministas, LGBT, povos do campo, pessoas com deficiência, povos e comunidades tradicionais, entre outros), que, a partir dos anos de 1980, no Brasil, contribuem para a entrada do olhar afirmativo da diversidade na cena social. Eles reivindicam que a educação considere, nos seus níveis, etapas e modalidades, a relação entre desigualdades e diversidade. Indagam o caráter perverso do capitalismo de acirrar não só as desigualdades no plano econômico, mas também de tratar de forma desigual e inferiorizante os coletivos sociais considerados diversos no decorrer da história.

A imbricação entre desigualdades e diversidade tem sofrido interpretações as mais diversas no contexto das relações de poder, nas quais se inserem as lutas sociais. São interpretações advindas tanto das políticas neoliberais que se acirraram no Brasil, nos países latino-americanos e em outros contextos do mundo a partir 
dos anos de 1990, quanto das lutas por identidade e reconhecimento desenvolvidas pelos próprios movimentos sociais, ações coletivas, organizações de caráter emancipatório e novos sujeitos sociais no mesmo período.

No terceiro milênio é possível dizer que estamos diante de uma mudança política e epistemológica, no que diz respeito ao entendimento sobre a imbricação entre desigualdades e diversidade que vai além do campo educacional. Trata-se de uma inflexão em nível nacional e internacional provocada por vários fatores, tais como: os questionamentos à globalização capitalista, a construção de uma rede internacional contra-hegemônica, os conflitos étnicos e religiosos na América Latina, Europa e Ásia, a formação e o fortalecimento das redes sociais e das novas mídias com foco na emancipação social, as lutas nacionais e transnacionais pelo direito à terra e ao território. Esses fatores se tornam mais incisivos quanto mais se intensificam, nacional e internacionalmente, fenômenos como: neocolonialismo, racismo, xenofobia, sexismo, homofobia e violência religiosa.

A pressão histórica dos movimentos sociais, somada a um perfil mais progressista de setores do Estado brasileiro nos últimos dez anos, trouxe mudanças no trato da diversidade no contexto das políticas públicas de caráter universal, desencadeando, inclusive, a implementação de políticas de ações afirmativas. Contudo, um dos limites que ainda persiste está no fato de que a maioria dessas ações ainda se limita às políticas de governo. Falta o seu enraizamento como políticas de Estado.

Mesmo assim, é possível afirmar que, nos últimos anos, no Brasil e na América Latina, com avanços e limites, algumas dimensões da diversidade pleiteadas historicamente pelos movimentos sociais e demais setores organizados da sociedade começam a fazer parte da pauta da agenda das políticas públicas. Transformam-se em temas de debate e de disputa na arena política e na própria produção intelectual. É nesse contexto que a discussão sobre a justiça social passa a ocupar mais espaço na produção teórica, na análise e na implementação das políticas públicas, entre elas, as educacionais.

O conjunto de artigos apresentados neste número temático analisa, problematiza e indaga a complexa relação entre desigualdades e diversidade na educação. A partir de diferentes abordagens e perspectivas educacionais, históricas, sociológicas, antropológicas e políticas, os autores e as autoras analisam essa desafiadora imbricação no contexto nacional e internacional.

O primeiro artigo, de Elsie Rockwell, Movimientos sociales emergentes y nuevas maneras de educar, discute a força dos movimentos sociais contemporâneos ao trazer para a sociedade indagações e questões sobre a relação desigualdade social e diversidade cultural e social gerada pelas recentes mudanças na economia e por projetos alternativos de vida e de formação. A autora destaca que, ao longo da história da classe 
trabalhadora, a formação de um "homem novo" tem sido um tema recorrente. Porém, a atual economia capitalista global tem gerado uma classe trabalhadora cada vez mais fragmentada e despossuída. Essa situação leva a uma reorganização social e se formam novos sujeitos sociais que retomam os recursos e as práticas culturais disponíveis, a fim de fortalecer os movimentos sociais emergentes. Conclui-se que o reconhecimento destes movimentos sociais e dos processos de formação tem transformado o pensamento iluminista, produzindo outras formas de pensar e atuar nos processos educativos.

Vera Maria Ferrão Candau, no seu artigo Direito à educação, diversidade e educação em direitos humanos, discute que os direitos humanos estão no centro da problemática das sociedades contemporâneas. Tendo por referência a tensão entre igualdade e diferença na concepção e prática dos direitos humanos, a autora analisa as especificidades, articulações e entrelaçamentos entre o direito à educação e a educação em direitos humanos, sendo esta última considerada atualmente como um componente fundamental do direito à educação. Esse contexto traz desafios aos processos educativos e à formação de sujeitos de direitos que considere suas especificidades e, ao mesmo tempo, fortaleça os processos democráticos, em que redistribuição e reconhecimento se articulem.

$\mathrm{O}$ artigo Movimento negro e educação: ressignificando e politizando a raça, de Nilma Lino Gomes, discute o papel do movimento negro brasileiro na ressignificação e politização da ideia de raça. A raça é entendida como construção social que marca, de forma estrutural e estruturante, as sociedades latino-americanas, em especial, a brasileira. Parte-se da premissa de que este movimento social, por meio de suas ações políticas, sobretudo em prol da educação, reeduca a si próprio, o Estado, a sociedade e o campo educacional sobre as relações étnico-raciais no Brasil, caminhando rumo à emancipação social. A ideia de raça analisada pela autora se assenta, ainda, na reflexão realizada pelos estudos pós-coloniais, que discutem a sua centralidade nos países com passado colonial e a sua operacionalidade nas relações de poder, as quais têm sido mantidas e subsistem no pensamento moderno ocidental, inclusive no educacional.

Maria Antônia de Souza, no artigo Educação do campo, desigualdades sociais e educacionais, caracteriza a gênese da prática e concepção da educação do campo, atentando para a concentração da terra e da propriedade como elementos estruturais geradores de desigualdade social. Destaca as principais conquistas efetivadas de 1990 até 2012 no âmbito da educação do campo e pontua conflitos judiciais em torno do direito à educação superior entre os povos do campo. Parte-se do pressuposto central de que esta educação é fruto de experiência coletiva construída pelos movimentos e organizações de trabalhadores do campo. 
No artigo Roteiro para uma história da educação escolar indígena: notas sobre a relação entre política indigenista e educacional, Luiz Antonio de Oliveira e Rita Gomes do Nascimento apresentam um roteiro para a história das políticas educacionais voltadas para os povos indígenas, a partir da consideração das suas relações com as políticas indigenistas. Destacam que a articulação entre os campos indigenista e da educação sugere pensar como as questões das diferenças culturais dos povos indígenas orientaram diferentes projetos de educação escolar indígena. Os autores partem do período "assimilacionista" e "civilizatório" do início do século XX, marcado pela ideia de uma necessária unidade da nação, passando pelas reformas desta política, em que é reconhecida a importância do ensino bilíngue nos processos de escolarização, até o momento atual, caracterizado pela busca do reconhecimento da diversidade cultural como direito fundamental, trazendo novos desafios para as políticas educacionais.

Choukri Ben Ayed, no artigo As desigualdades socioespaciais de acesso aos saberes: uma perspectiva de renovação da sociologia das desigualdades escolares, analisa o avanço dos conhecimentos sobre as desigualdades socioespaciais de acesso aos saberes na França. Segundo o autor, embora este objeto envolva muitas questões societais, as pesquisas empíricas a ele consagradas continuam embrionárias. Na sua argumentação, Ben Ayed insiste tanto no que está em jogo, metodologicamente, no estudo das variações do aprendizado escolar em função dos contextos de escolarização, quanto na necessidade de não dissociar, nas análises, o impacto dos fatores sociais e espaciais. Reconhece que, hoje, um dos desafios da renovação das abordagens na sociologia da educação consiste em levar em conta uma combinação desses dois fatores.

O artigo Novos olhares para as desigualdades de oportunidades educacionais: a segregação residencial e a relação favela-asfalto no contexto carioca, de Mariane Campelo Koslinski e Fatima Alves, discute a tradição de estudos quantitativos que tiveram origem no Relatório Coleman (1966) e seus desdobramentos nos estudos de efeito escola e, posteriormente, de efeito vizinhança. As autoras focam a sua análise nos limites e possibilidades trazidos pela literatura de efeito vizinhança e da geografia de oportunidades para a compreensão de mecanismos mediadores entre a segregação residencial e resultados escolares. Discutem estudos que partiram desse arcabouço teórico e metodológico, focalizando o contexto brasileiro. Ao final, apresentam os próximos desafios para se avançar na compreensão da organização social do território e as desigualdades educacionais nesse contexto.

Mônica Carvalho Magalhães Kassar, no artigo Educação especial no Brasil: desigualdades e desafios no reconhecimento da diversidade, argumenta que abordar a educação especial no Brasil implica considerar a política educacional proposta nos últimos anos pelo governo federal e, especialmente, a presença nas escolas de diversas populações que constituem o país de formas historicamente desiguais. A partir dessas 
considerações, a autora analisa as mudanças registradas na educação das populações marginalizadas no processo escolar, especialmente de pessoas com deficiências, e reflete sobre os limites ainda presentes na educação brasileira, incluindo as complexas relações que envolvem os lugares da diferença nas proposições legais e nas práticas escolares.

No artigo Subjetividade docente, inclusão e gênero, Maura Corcini Lopes e Maria Cláudia Dal'Igna discutem de que modos o gênero opera como elemento organizador das subjetividades docentes e do desempenho escolar em tempos de inclusão e de governamentalidade neoliberal. Governamentalidade, subjetividade e gênero são as ferramentas teórico-metodológicas adotadas pelas autoras para examinar de que formas algumas práticas de governamento estão implicadas na produção de diferenças de gênero, no que se refere ao desempenho escolar, e na constituição das subjetividades docentes inclusivas. Duas pesquisas fornecem subsídios para sustentar a argumentação das autoras: uma que objetiva conhecer como docentes são subjetivados pelas práticas de inclusão; outra que investiga como o gênero atravessa e constitui a prática docente.

Néstor López, em Adolescentes en las aulas: la irrupción de la diferencia y el fin de la expansión educativa, inicia o seu artigo com uma revisão das recentes tendências de escolarização dos adolescentes na América Latina, enfatizando em que medida a expansão da escolarização desde o início dos anos de 1990 se traduziu em uma significativa redução das desigualdades de acesso à educação e, ao mesmo tempo, como a desaceleração do processo de escolarização vivido nos últimos anos reinstala o desafio das desigualdades como elemento central da agenda educativa. Em seguida, o autor levanta algumas hipóteses em torno das causas dessa desaceleração visível nos processos de universalização do acesso à escola, enfatizando aquelas que centram a sua atenção nas desigualdades resultantes da impossibilidade dos sistemas educativos operarem em contextos de crescente diversidade cultural e identitária, evidenciando a persistência de múltiplos mecanismos cotidianos e naturalizados de discriminação nas práticas das instituições escolares.

O artigo Há algo novo a se dizer sobre as relações raciais no Brasil contemporâneo?, de Valter Roberto Silvério e Cristina Teodoro Trinidad, discute o contexto da aprovação da Lei n. 10.639/2003 e suas diretrizes, alterando a Lei de Diretrizes e Base da Educação Brasileira (LDB), que pressupõem um conjunto de mudanças substantivas que passam a alterar a política pública educacional no país. Segundo os autores, a obrigatoriedade da educação das relações étnico-raciais e do ensino de história e cultura afro-brasileira e africana em toda a educação básica é resultado do reconhecimento da discriminação racial e do racismo, como constitutivos de nossa formação social, e permite desvendar as contribuições das culturas africanas na constituição de nossa brasilidade para além do trabalho escravo. A identidade 
negra, produto político do apagamento da multiplicidade cultural de povos que aportaram no país, passa a dar lugar ao prefixo "afro" como possibilidade de novas identificações e recriações dos brasileiros descendentes de africanos, as quais podem ser analisadas a partir do conceito de Diáspora.

Para adensar ainda mais a rica discussão aqui realizada, apresentamos a entrevista com Boaventura de Sousa Santos, concedida à Júlia F. Benzaquen, sobre $A$ Universidade Popular dos Movimentos Sociais, seguida da resenha do livro de Miguel G. Arroyo, Currículo, território em disputa, escrita por André Marcio Picanço Favacho. Entrevista e resenha abordam as principais reflexões de dois brilhantes intelectuais sintonizados com a dinâmica do nosso tempo e sempre alertas aos desafios trazidos pela relação entre desigualdades e diversidade no campo educacional e na sociedade como um todo.

Cabe ressaltar, ainda, que a temática da diversidade já esteve presente entre as edições da revista Educação \& Sociedade no dossiê "Diferenças", dez anos atrás. De lá para cá, a construção das diferenças se complexificou e passou a tensionar ainda mais as práticas educativas, o Estado e suas políticas, por meio da ação dos sujeitos sociais. Esse contexto trouxe novos entendimentos sobre o tema, outras perspectivas de análise e tem produzido um instigante debate teórico e político. Um dos desafios colocados é a compreensão das diferenças como constituintes do complexo processo da diversidade e a sua imbricação com as desigualdades.

Espera-se que o debate intelectual com o qual o leitor e a leitora terão contato nas páginas dessa Revista possa provocar, adensar e fazer avançar a discussão sobre o tema central aqui proposto.

Nilma Lino Gomes

(Organizadora)

\section{Referências}

ABRAMOWICZ, A.; RODRIGUES, T.C.; CRUZ, A.C.J. A diferença e a diversidade na educação. Contemporânea, São Carlos, n. 2, p. 85-97, ago.-dez. 2011.

BRASIL. Constituição da República Federativa do Brasil de 1988. Disponível em: <http:// www.planalto.gov.br/ccivil_03/constituicao/constitui\%C3\%A7ao.htm>. Acesso em: 20 set. 2012.

SANTOS, B.S. A construção intercultural da igualdade e da diferença. In: SANTOS, B.S. A gramática do tempo. São Paulo: Cortez, 2006. p. 279-316. 